\title{
Laboratory techniques in the diagnosis of syphilis: A review
}

\author{
J J van der Sluis
}

\begin{abstract}
Introduction
At present, the laboratory diagnosis of syphilis is based on the visualisation of the pathogen, Treponema pallidum and/or the demonstration of specific antibodies in body fluids by means of serological tests. In this article the current methods, the test procedures that have only recently been introduced to diagnose syphilis and the diagnosis based on molecular biology techniques are reviewed.
\end{abstract}

\section{Visualisation of the pathogen}

The diagnosis of syphilis by direct visualisation of the causative organism is complicated, since at present $T$ pallidum cannot be routinely cultivated in vitro on artificial media. ${ }^{1}$ Treponemes can be observed in exudates of primary and secondary lesions and in fluid obtained from lymph node puncture upon dark-field microscopy. ${ }^{2}$ Recently, darkfield examination of amniotic fluid obtained by amniocentesis has been shown to be valuable in the diagnosis of congenital syphilis. ${ }^{34}$ The treponemes are recognised by their characteristic morphology and motility. The preparations should be examined with minimal delay because of the poor retention of motility of the treponemes in vitro. The direct or indirect fluorescent method is a suitable alternative if direct dark-field microscopy is not possible. ${ }^{5-7}$ The visualisation of $T$ pallidum by either method is diagnostic, provided that non-venereal treponematoses are excluded.

Rabbit infectivity testing (RIT) for routine diagnostic purposes with materials from suspected patients is impractical since the development of orchitis and/or seroconversion in the rabbit takes rather long and appropriate facilities to house and handle the rabbits are necessary. However, RIT is the only test available to demonstrate the presence of virulent treponemes. ${ }^{8}$

\section{Histochemistry and Immunohistochemistry}

Treponemes can be observed in formalin-fixed and paraffin embedded biopsy material using silver impregnation methods such as the Whartin-Starry ${ }^{9}$ or the Steiner method. ${ }^{10}$ Immunological recognition of $T$ pallidum in paraffin embedded tissues has been described. ${ }^{56} \mathrm{An}$ immunogold staining technique for this purpose has recently been published. ${ }^{11}$

Dermato-Venereology, Erasmus University, PO Box 1738, 3000 DR Rotterdam, The Netherlands

$\mathrm{J} J$ van der Sluis

Accepted for publication 16 July 1992
An ideal serological test for syphilis should have high sensitivity and specificity. In addition, such a test should be suitable for treatment-monitoring and give negative results after adequate therapy to allow a clear-cut diagnosis of reinfection. Such an ideal test is not yet available and serological testing relies on testing individuals with screening tests, followed by confirmation of the results by confirmatory tests. In screening, it is important not to miss individuals who are infected. Therefore, high emphasis is placed on the sensitivity of the test and on a high negative predictive value (NPV) of a test result. Confirmatory tests are used to distinguish true positives and true negatives among the individuals traced by the screening tests. High emphasis, therefore, is placed on the specificity and on a high positive predictive value (PPV) of test results. (For calculating NPV and PPV, see ref 12). In addition to these theoretical considerations, technical and economic aspects also play a role. These include technical simplicity, rapidity, the ease of performing IgM-based diagnostic tests, suitability for automation and financial costs.

Currently, two types of tests, namely the nontreponemal and the treponemal tests are used to determine the presence of antibodies for the serodiagnosis of syphilis. The nontreponemal tests use cardiolipin as the active ingredient in a mixture with cholesterol and lecithin to detect anticardiolipin antibodies. The Centers for Disease Control (CDC, Atlanta, Georgia, U.S.A.) recognise five nontreponemal tests as Standard Tests for Syphilis. ${ }^{13}$ These five tests have the same standardised antigen and consequently have a similar sensitivity, which varies from approximately $70 \%$ in primary syphilis to $100 \%$ in secondary syphilis. The specificity varies considerably depending on the occurrence of acute and chronic biological false-positive (BFP) reactions in the population under investigation. False-negative results may occur owing to the prozone phenomenon, which is caused by high levels of anti-cardiolipin antibodies. Upon dilution of these sera positive results are obtained, usually at high titre.

Among these five nontreponemal tests two categories can be distinguished. One category comprises those tests which can be read visually, because of the presence of a coloured substance in the antigen preparation. These tests comprise the Reagin Screen Test (RST), the Toluidin Red Unheated Serum Test (TRUST) and the Rapid Plasma Reagin (RPR) card test. The latter test, which was initially developed for field use, is the most widely used nontreponemal test. It is performed on plastic coated cards onto which circles have been imprinted. When performed 
qualitatively, standardised amounts of undiluted serum and antigen suspension containing carbon particles are mixed within the circle and spread over it. When performed quantitatively, serially diluted serum is mixed with the antigen. The card is then mechanically rotated at $100 \mathrm{rpm}$ for $8 \mathrm{~min}$ under humid conditions. When a serum contains anticardiolipin antibodies, flocculation occurs and the carbon particles coagglutinate. The test results are read under a high intensity light source in the humid state immediately after rotation and scored as reactive or nonreactive. The quantitive results are expressed as the reciprocal of the highest dilution giving a reactive result.

The second category comprises the Venereal Disease Research Laboratory (VDRL) slide test and the Unheated Serum Reagin test which have to be read using a microscope. In the VDRL slide test freshly prepared antigen and serum which had been heated at $56^{\circ} \mathrm{C}$ for $30 \mathrm{~min}$ are used. The test is performed in a very similar manner to that of the RPR: standard amounts of serum and antigen are mixed within a ring on a glass slide by rotating of the slide mechanically. If anti-cardiolipin antibodies are present, the short antigen rods aggregate to form clumps which can be observed microscopically. A quantitative VDRL is performed with serial dilutions, usually up to $1: 64$, of the test serum. The VDRL test is the only test recommended for investigating cerebrospinal fluid (CSF). There is no need to heat-inactivate CSF before use.

Tests for detecting anti-lipoidal antibodies are used for screening. Their titres expressed as the reciprocal of the highest dilution giving a positive result, usually decrease spontaneously in time. The decline after treatment is used for treatment-monitoring.

The treponemal tests measure specific antibodies formed by the host in response to infection with $T$ pallidum. In the haemagglutination tests (MHA-TP, HATTS and TPHA) erythrocytes coated with antigens derived from the Nichols strain of $T$ pallidum are used. The suspension of these erythrocytes in diluted serum containing anti-treponema antibodies results in agglutination of the red cells, which can be read visually. Despite fairly complicated absorbing diluents provided with the kits, non-specific reactions do occur. The haemagglutination tests are suitable for testing large numbers of samples since they are simple to set up and easy to read. ${ }^{13}$

The most widely used treponemal test is the fluorescent treponema antibody absorbtion (FTA-ABS) test. ${ }^{14}$ Whole micro-organisms are fixed to glass slides and are overlaid with previously absorbed test serum. Antibodies bound to the treponemes are preferably detected with an anti-IgG conjugate. A serum dilution of 1:5 in sorbens prepared from the culture medium of Reiter treponemes or from a sonicate of the latter ${ }^{15}$ results in an extremely sensitive test, especially in early syphilis. However, false-positive results due to high immunoglobulin levels ${ }^{17}$ or anti-nuclear antibodies ${ }^{18}$ in the test sera do occur. The FTA-ABS test is at present the confirmatory reaction of choice and is used as the gold standard. Varieties of the test are used to diagnose congenital syphilis and to determine the activity of the disease. A category is the (IgM)FTA-ABS test in which an anti-IgM conjugate is used for the detection of antitreponemal IgM antibodies. ${ }^{19}$ In the $19 S(\operatorname{IgM})$ FTA-ABS test, the 19S (=IgM containing) fraction from the test sera is used to avoid false-positive reactions caused by rheumatoid factor (Rf). ${ }^{20}$ However, the FTA-ABS test is technically complicated and requires continuous quality control checks in order to obtain reliable and reproducible results. Moreover, each test result has to be read individually by an experienced observer. This excludes automation and processing of large numbers of sera and may introduce subjectivity in interpreting the results.

Treponemal tests are performed qualitatively. Once positive, the test results usually remain so for many years and often lifelong Hence these tests are not suitable for monitoring the effect of treatment.

Shortcomings of the present tests are their insufficient sensitivity and/or specificity in the diagnosis of incubating primary syphilis, congenital syphilis and neurosyphilis and their inability to distinguish between venereal and nonvenereal treponematoses. Moreover, since co-infections with human immunodeficiency virus (HIV) can change the outcome of serological test for syphilis, methods that can detect (parts of) the syphilis pathogen are desirable. From a technical and economic point of view, automated tests which would be suitable for screening, confirmation purposes and treatment monitoring would be welcome.

\section{Application of ELISA}

The enzyme-linked immunosorbent assays (ELISA) are widely used in the field of infectious diseases owing to the possibility of automation and the broad potential to detect antibodies, antigens and haptens (for a recen review see ref 21). After the first use of the indirect ELISA in the serodiagnosis of syphilis, ${ }^{22}$ several related tests in which detergent extracted or sonicated $T$ pallidum (Nichols) were used as an antigen have been reported. ${ }^{23-27}$ Indirect ELISA in which component from non-pathogenic treponemes ${ }^{28}$ or modified VDRL antigen ${ }^{29}$ were used as an antigen have been developed. Besides use in (congenital) syphilis, ${ }^{30}$ the latter tests have also been used to distinguish the anti-cardiolipin antibodies in syphilis from the anti-phospholipid antibodies in other diseases. ${ }^{31-34}$ In the figure a schematic representation of some ELISA tes principles is depicted.

Two tests, based on the indirect ELISA principle and in which antigens from $T$ pallidum (Nichols) are used are commercially available. The Syphilis Bio-EnzaBead assay (Organon Teknika Corp.) has ferrous metal beads coated with antigens from $T$ pallidum as the solid phase. The steps in the ELISA procedure are performed by the subsequent transfer of the beads into separate microtitre plates containing dilutions of the test sera and 
A

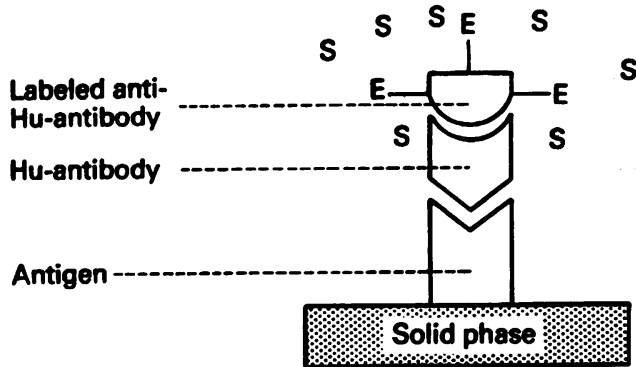

B

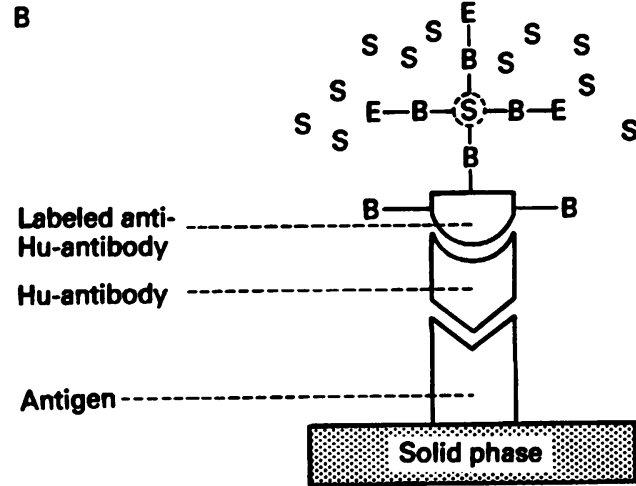

C

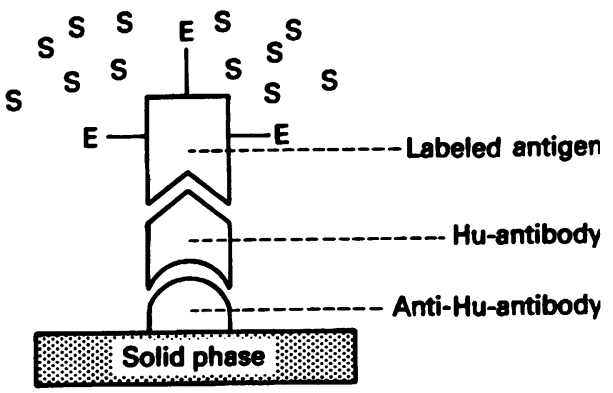

Figure Schematic representation of different ELISAs. A. Indirect ELISA.

Antibodies, if present in the test serum will bind to the antigen, coated onto the solid phase. Incubation with enzyme-labelled anti-human antibodies (polyclonal or monoclonal), followed by the incubation with the substrate for the enzyme results in the development of a colour, the intensity of which is a measure for the amount of antibodies present in the test serum. It is understood that extensive rinsing is needed between the various incubations to remove unbound substances.

B. Amplified indirect ELISA.

The initial steps are as above. In the scheme depicted here, the detection of the antibodies bound to the antigen is performed with the streptavidin-biotin-enzyme complex.

Streptavidin has four binding sites for biotin. The complex is prepared in such a manner that streptavidin retains a

free binding site for the binding of the biotin-labelled antibody. Since the enzyme is labelled with several biotin molecules, additional complexes can bind to the

biotin-labelled molecules, amplifying the sensitivity further.

Other amplification systems use enzyme-labelled

streptavidin that combines with the biotin-labelled antibody.

C. Antibody capture ELISA

Affinity purified antibodies specific for a class of human antibody are coated onto the solid phase. Incubation with a test serum results in the capture of antibodies of that class. The presence of antigen-specific antibodies among these antibodies is investigated by incubating with the antigen, which is labelled with an enzyme. Incubation with the substrate results in the development of a colour.

Symbols:

E : Enzyme

$S$ : Substrate

(St: Streptavidin

$B:$ Biotin control sera, washing fluids, conjugate solution and finally the substrate solution by means of a magnetic transfer device. This test, which has provisional status as Standard Test for Syphilis (C.D.C.) was evaluated by four groups. ${ }^{35-38}$ The results are difficult to compare owing to a lack of a final reading procedure and only one reporting group separated the results on the basis of treatment. In this latter study the specificity of the test was $94.7 \%$ and that of the FTA-ABS test $98 \cdot 1 \%$. The sensitivity in FTAABS positive primary and secondary syphilis was $100 \%$ and in early latent and late latent syphilis it was $96.4 \%$ and $84.6 \%$ respectively.

The second test is the Captia Syphilis-G test (Mercia Diagnostics, Guildford, Surrey). The antigen is coated onto the wells of a microtitre plate. After incubation with 20 -fold diluted sera and rinsing, bound anti-treponemal IgG is detected with a tracer complex consisting of biotinylated monoclonal antibody to human IgG and streptavidin conjugated to horseradish peroxidase. This detection system provides an amplification of the final signal. In their evaluation of the test, Young et $a l^{39}$ observed an overall sensitivity of $98.4 \%$ and a specificity of $99.3 \%$. In the group of patients investigated by Lefevre et $a l^{40}$ the Captia Syphilis-G test showed an overall sensitivity of $98.3 \%$. In the patients with secondary, early and late latent, neuro- and congenital syphilis and in reinfected patients, the test reached a sensitivity of $100 \%$. The samè sensitivity was observed in VDRL-reactive and VDRL-nonreactive treated patients. The sensitivity in patients with untreated primary syphilis was $82 \%$. Falsepositive reactions occurred in $1.5 \%$ of the patients. All 92 sera, shown to contain Rf were negative in the Captia Syphilis-G assay. ${ }^{41}$ The sensitivity of $82 \%$ of the Captia Syphilis-G assay in primary syphilis did not differ from the sensitivity of $84 \%$ in the combined screening with the TPHA and the VDRL tests. The authors concluded that the Captia Syphilis-G assay can be used as a single screening test for syphilis. $^{42}$

A third commercially available test is the Captia Syphilis-M test (Mercia Diagnostics, Guildford, Surrey), which is based on the capture ELISA principle. In this test a separation between IgG and IgM is accomplished by the capture of IgM from the test sera by antibodies to human IgM that have been coated onto the wells of microtitre plates. This separation is essential in IgM-based diagnoses to circumvent false-positive reactions caused by $R f$ in the test sera. ${ }^{434}$ The captured IgM is detected with treponemal antigens labelled with an enzyme. This test was evaluated by Lefevre $e t a l^{40}$ and IJsselmuiden $e t a l .^{45}$ The results of both groups agreed reasonably well considering the small numbers of patients tested. The sensitivity was highest in patients with untreated primary syphilis $(94 \%$ and $82 \%$ respectively) and it gradually decreased when the stage of the disease progressed. Lefevre et $a l^{40}$ noted that patients with late latent syphilis were unreactive in this test. There was a remarkable difference in sensitivity between the groups of patients with VDRL-reactive and 
VDRL-nonreactive treated latent syphilis. In the former group, the sensitivity was $30.4 \%$ and in the latter group it was $3 \cdot 8 \%$. ${ }^{40}$ Both groups of investigators observed positive results in all cases of congenital syphilis. Falsepositive reactions in newborns from mothers who had been adequately treated for syphilis were not observed. ${ }^{45}$ The test was also negative in individuals in whom false-positive reactions in the VDRL test were observed. ${ }^{45}$ Two of the six individuals with $R f$ in their serum reacted positively in the Captia Syphilis-M showing that the specificity of this test was not absolute. $^{40}$

Application of molecular biology techniques

The application of molecular biology techniques to the diagnosis of syphilis thus far has served two aims:

1. The production of large quantities of treponemal proteins which can serve as antigens in serodiagnostic tests.

2. Amplification of selected treponemal DNA sequences from selected material using the polymerase chain reaction (PCR). The number of copies of this selected treponemal DNA are thus increased to enable detection using specific probes.

Test with antigens derived via the recombinant DNA technology

An assay based on the indirect ELISA in which the $4 \mathrm{D}$ membrane protein with a molecular mass of $190 \mathrm{kDa}$ derived via the recombinan DNA technique was published by Radolf $e t$ $a .^{46}$ In this assay anti-treponemal IgG in sera was measured. All 172 VDRL-negative control sera and the sera from 20 individuals with VDRL-positive BFP reactions were negative, indicating a very high specificity. The authors noted an extremely low optical density with these sera which they assumed to be due to the use of a purified recombinant antigen rather than whole $T$ pallidum sonicate. With stored sera from syphilis patients, all treated less than 3 months before, the 4D ELISA reached a sensitivity of $81 \%$ in primary syphilis and $100 \%$ in secondary and early latent syphilis. In patients with late latent syphilis the sensitivity was $86 \%$. However, in patients with cardiovascular and neurosyphilis the test showed a sensitivity of $57 \%$. Using fresh sera from a group of patients with dark-field positive primary syphilis, the 4D ELISA showed a sensitivity of $83 \%$ and that of the VDRL and the FTA-ABS test both reached $88 \%$. Eighty percent of the sera from yaws patients and $73 \%$ of the sera from patients with pinta were positive in the $4 \mathrm{Da}$ ELISA. This suggested the presence of a molecule similar to the $4 \mathrm{D}$ molecule in $T$ pertenue and $T$ carateum, but also showed that a test based on the 4D antigen is unable to distinguish serologically between infections caused by the three treponeme species. The authors suggested that the sensitivity of reombinant antigen based ELISA can be improved further by including additional cloned $T$ pallidum antigens which are immunogenic in all stages of syphilis.

A second study assessed a $37 \mathrm{kDa}$ treponemal protein expressed in $E$ coli for its diagnostic value in a radioimmunoassay. ${ }^{47}$ In a group of 81 treated and untreated patients with various stages of syphilis, 71 sera reacted positively with the $37 \mathrm{kDa}$ protein resulting in a sensitivity of $87 \cdot 7 \%$, while the FTA-ABS test showed a sensitivity of $100 \%$. The specificity of the test was $95.4 \%$. In a group of 50 sera from patients with untreated primary syphilis, 38 were reactive with the $37 \mathrm{kDa}$ protein resulting in a sensitivity in primary syphilis of $76 \%$. The sensitivity of the FTA-ABS test was $86 \%$ in this group. Four out of 42 sera from BFP reactors reacted positively with the $37 \mathrm{kDa}$ protein, while all sera were negative in the FTA-ABS test.

Schouls $e t a l^{48}$ evaluated two recombinant DNA products, namely the $42 \mathrm{kDa}$ treponemal membrane protein A (TmpA) and the 34 $\mathrm{kDa}$ treponemal membrane protein $\mathrm{B}(\mathrm{TmpB})$ for use in the serodiagnosis of syphilis. TmpB was found to be unsuitable as a single antigen because a considerable portion of the sera from patients with syphilis did not react with TmpB. In the TmpA-ELISA, 21 out of 24 (87.5\%) sera of patients with untreated primary syphilis, all FTA-ABS positive, were also positive in the TmpA-ELISA. The sera from patients with untreated secondary syphilis $(n=25)$ and latent syphilis $(n=19)$ reacted positively in the TmpA and were also positive in FTA-ABS, TPHA and VDRL tests. Sera from patients with treated syphilis were divided into groups with a positive VDRL $(n=30)$ and a negative VDRL $(n=30)$. In the VDRL-reactive group, 25 sera were positive in the TmpA-ELISA, while in the VDRL-nonreactive group, 10 sera were positive. The authors observed a correlation between the VDRL-titre and the presence of anti-TmpA antibodies and suggested that in addition to screening, the TmpA-ELISA would also be useful for monitoring the effect of therapy. This suggestion was investigated by IJsselmuiden et al. ${ }^{49}$ In this study the TmpAELISA had a sensitivity of $76 \%(42 / 55)$ in untreated primary syphilis, a sensitivity of $100 \%$ in secondary and of $98 \%$ in early latent syphilis. The lower sensitivity in primary syphilis in this study was due to the incorporation of dark-field positive but FTA-ABS negative patients. In treated VDRL-reactive syphilis patients, the TmpA-ELISA had a sensitivity of $85 \%$ and in VDRL-nonreactive syphilis patients a sensitivity of $37 \%$. In a group of 27 patients with VDRL-reactive syphilis, it was shown that in the sera from 25 patients with early syphilis, the kinetics of the decline in antiTmpA antibodies paralleled the decline in anti-cardiolipin antibodies in response to therapy. The two exceptions were the sera from a patient with late latent syphilis and from a patient with asymptomatic neurosyphilis. The authors recommended the TmpA-ELISA assay (commercially available from EuroDiagnostics, Apeldoorn, The Netherlands) as a screening test which would also be suitable for treatment-monitoring.

Application of PCR technique to the diagnosis of syphilis

The polymerase chain reaction has been used 
by Hay et al. ${ }^{5051}$ to detect DNA sequences specific for pathogenic treponemes in cerebrospinal fluid (CSF). Sequences of 519 and 428 base pairs (bp) from the TmpA and 4D genes respectively were amplified. Using the method, it was possible to detect 65 organisms in $0.5 \mathrm{ml} \mathrm{CSF}$ as determined by diluting suspensions of Nichols treponemes. The specificity using $30 \mathrm{CSF}$ specimens from individuals not suspected of HIV infection or syphilis was at least $96 \cdot 7 \%$. From the 19 CSF specimens examined for latent or tertiary syphilis, 10 (53\%) were positive. Twenty-eight specimens obtained from HIV-positive patients, of whom 14 had "CNS disease" were tested for the presence of treponemal DNA. Seven patients from the CNS disease group were positive. From the remaining seven patients in the CNS disease group and from the 14 patients without CNS disease, three and five patients respectively had a history of syphilis. None of these 21 patients were positive using the PCR technique. Noordhoek et $a l^{52}$ used PCR to detect treponemal DNA in CSFs from 27 patients with untreated symptomatic and asymptomatic neurosyphilis. The gene for the $39 \mathrm{kDa}$ basic membrane protein was chosen for amplification. This was performed in two parts. In the first part the primers allowed the amplification of a $617 \mathrm{bp}$ fragment, in the second part a second primer set (nested primers) allowed amplification of a $500 \mathrm{bp}$ fragment from the previously amplified $617 \mathrm{bp}$ fragment. With this PCR method, it was possible to detect that amount of isolated treponemal DNA which was equivalent to a single treponeme and a minimum of 100 treponemes per $\mathrm{ml}$ when suspended in CSF. Specificity was assessed using a large variety of microorganisms including Borrelia burgdorferi. Specific amplification was only noted with DNA from $T$ pallidum ssp pallidum and pertenue. Positive results were obtained with CSFs from five out of seven patients with acute neurosyphilis. None of the four patients with chronic neurosyphilis but two out of 16 patients with asymptomatic neurosyphilis were positive. However, CSFs obtained up to three years after treatment were frequently positive using PCR. This was rather puzzling since none of the patients showed evidence of active disease following treatment and the titres in the serological tests declined slowly.

Burstein $e t a l^{53}$ amplified a 658 bp portion of the gene coding for the $47 \mathrm{kDa}$ membrane protein. The probe used to detect the amplified DNA by hybridisation consisted of a large 496 bp fragment included in the amplified DNA. Using this method, the authors were able to detect treponemal DNA in some samples calculated to contain a single treponeme. Special attention was paid to DNA that could possibly contaminate clinical isolates. No specific amplification products were obtained from any of the tested skin microbes, central nervous system pathogens and microbes causing STD. Specific amplification occurred only with the DNA from $T$ pallidum ssp pertenue. Positive PCR results, confirmed by RIT were obtained with the amniotic fluid from the two pregnant women with untreated syphilis, with the serum and the CSF from the patient with untreated early latent syphilis, but whose CSF showed normal clinical laboratory tests and with the CSF from the patient with syphilitic meningitis. The CSFs from two patients with general paresis were negative.

The study by Grimprel $e^{2} \mathrm{al}^{54}$ focused on the inhibition of PCR by contaminants in clinical samples to optimise the method for the diagnosis of congenital syphilis. This inhibition was noted in a previous report, especially when larger volumes were used for amplification. ${ }^{53}$ Four different methods were used to prepare DNA prior to amplification: a boiling method, a low spin centrifugation method, the alkaline lysis extraction method and a spin extraction method. The authors suggested that preparation of DNA from amniotic fluids should be performed by the boiling and the low spin centrifugation method. For neonatal CSF and sera the simple boiling method should be initially used with 10 and $20 \mu \mathrm{l}$ volumes and if necessary, followed by the low spin centrifugation method. The method showed a specificity of $100 \%$ indicating that false-positive results due to contamination of the samples during collection and processing had not occurred. The sensitivity of the PCR, as compared with RIT was $100 \%$ for amniotic fluids, $71 \%$ for neonatal CSFs and $68 \%$ for sera. An interesting aspect was the detection of an in utero treatment failure. Used in this manner, the PCR technique would be useful to establish optimal treatment schedules for congenital syphilis.

Attempts to distinguish sub-species of $T$ pallidum Recombinant DNA studies showed a single base pair difference between the genes tpf-1 and tyf-1 which code for homologous sub-units of the $190 \mathrm{kDa}$ proteins of $T$ pallidum ssp pallidum and ssp pertenue respectively. ${ }^{55}$ This difference was exploited in attempts to distinguish between DNA extracted from rabbit derived $T$ pallidum ssp pallidum and ssp pertenue after amplification using the PCR technique. DNA from three of the four $T$ pallidum ssp pallidum strains contained the "pallidum" trait. In five out of the six strains of $T$ pallidum ssp pertenue the "pertenue" trait was present. This indicated that the observed difference between the tpf-1 and tyf- 1 genes did not constitute a definite trait for either $T$ pallidum sub-species. ${ }^{56}$ The sera from patients with syphilis and yaws could not be distinguished in the ELISA in which two synthetic homologous oligopeptides of 15 amino acids each reflecting the one base pair difference were used as antigens. $^{57}$

\section{Discussion}

Screening is performed by a single lipoidal test, usually the VDRL (USA) or a screening combination of VDRL and TPHA (Europe). Neither test can be fully automated easily and the results are subjective and recorded manually. Fully automated tests in which these two aspects are incorporated would reduce the 
work-load considerably, especially for testing large numbers of sera. Tests based on the ELISA methodology offer this possibility. The Captia Syphilis-G test was initially recommended as a confirmatory test because of its sensitivity in primary syphilis of $82 \% .^{40}$ This test was recommended as a single screening test when it was shown that this did not differ significantly from the sensitivity of the combined screening with VDRL and TPHA. ${ }^{42}$ It has a sensitivity of $100 \%$ in treated and untreated secondary, latent and late syphilis. Since the test has a sensitivity of $100 \%$ in VDRL-reactive and VDRL-nonreactive treated syphilis at all stages, the test would be unsuitable for treatment-monitoring. For this purpose, the VDRL can be used, but the Captia Syphilis-M test has been recommended as an alternative. ${ }^{40}$ This test has been recommended for the diagnosis of congenital syphilis ${ }^{45}$ and offers the possibility of IgM-based diagnosis outside the setting of specialised laboratories. A disadvantage is the specificity, which is not absolute in sera containing $\mathbf{R f}^{40}$ The Syphilis Bio-EnzaBead test, designed as a confirmatory test was evaluated by four groups. In these studies the Bio-EnzaBead test had a somewhat lower specificity than the FTA-ABS test. This does not favour the replacement of the latter by this test. The test showed a lower sensitivity in treated syphilis as compared with the FTAABS and the MHA-TP. This indicated that the test may be valuable in treatment-monitoring. However, the time period between treatment and nonreactive test results requires further investigations. $^{38}$

From the three published tests in which a recombinant DNA protein was used as an antigen, only the TmpA-ELISA was evaluated as a diagnostic test. This test had a high sensitivity in untreated patients. However, in treated patients the sensitivity varied. The sharp decrease in the anti-TmpA antibodies within a year after treatment correlated with the decline in VDRL titre. For this reason, the authors recommended this test for screening and for monitoring the effect of treatment. ${ }^{489}$ PCR seems pre-eminently suitable for detecting DNA from low numbers of treponemes in clinical samples. The few PCR studies published focused on the diagnosis of congenital and neurosyphilis. In two studies it was shown that the method of preparing DNA prior to amplification has to be considered in order to remove or inactivate contaminants in the clinical material which would otherwise inhibit the DNA polymerase reaction catalysed by the Taq polymerase. ${ }^{5354}$ The results of optimised PCR method showed a good correlation with RIT using amniotic fluids. Notably, the amniotic fluid from both pregnant women with primary syphilis showed negative PCR- and RIT results. The number of positive PCR results was considerably less with neonatal CSFs and sera.

Both PCR studies with CSF from patients with untreated late syphilis showed a large difference in the overall positive rate $(53 \%$ versus $26 \%$ ). Unfortunately, RIT was not performed in these studies. However, the results differ from the RIT results with the CSFs from patients with late syphilis in the study by Lukehart et al. ${ }^{58}$ Furthermore, the presence of treponemal DNA in CSFs from intravenously treated patients stressed the importance of simultaneous RIT studies. The question as to whether the presence of treponemal DNA reflects the presence of virulent treponemes or DNA from dead treponemes is highly relevant for investigating patients in whom the serological detection of syphilis is hampered by coinfection with HIV. ${ }^{59-61}$ Further studies are necessary to establish the exact value and place of PCR technique in the armament of currently used diagnostic tests for syphilis.

1 Fieldsteel AH, Cox DL, Moeckli R. Cultivation of virulen Treponema pallidum in tissue culture. Infect Immun 1981;32:908-15.

列 KK, Mardh PA Sparling PF, Wiesner PJ, Cates ir W, Lemon SM, Stamm WE (eds). Sexually Transmitted Diseases, 2nd ed. New York: McGraw-Hill 1990:927-34.

3 Wendel GD, Maberry MC, Christmas JT, Goldberg MS, Norgard MV. Examination of amniotic fluid in diagnosing congenital syphilis with fetal death. Obstet Gynecol congenital syph $1989 ; 4: 967-70$.

4 Wendel GD, Sanchez PJ, Peters MT, Harstad TW, Potter LL, Norgard MV. Identification of Treponema pallidum in amniotic fluid and fetal blood from pregnancies complicated by congenital syphilis. Obstet Gynecol $1991 ; 8: 890-4$.

5 Ito F, Hunter EF, George RW, Swisher BL, Larsen SA Specific immunofluorescence staining of Treponema pallidum in smears and tissues. $f$ Clin Microbio 1991;29:444-8.

6 Ito F, Hunter EF, George RW, Pope V, Larsen SA. Specific immunofluorescent staining of pathogenic treponemes with a monoclonal antibody. $₹$ Clin Microbiol 1992;30:831-8.

7 Wilkinson $A E$, Cowell LP. Immunofluorescent staining for the detection of Treponema pallidum in early syphilitic lesions. Br f Venereal Dis 1971;47:252-4.

8 Turner TB, Hardy PH, Newman B. Infectivity tests in syphilis. Br fVenereal Dis 1969;45:183-96.

9 Lillie RD, Fulmer HM. Histopathologic Technic and Practical Histochemistry. 4th ed. New York: McGraw-Hil 1976:761

10 Steiner G. Modified silver stain for micro-organisms in tissue. Am f Clin Pathol 1950;20:489-90.

11 Beyer-Patterson P, Abramowsky C. Immunogold stainin technique for demonstration of Treponema pallidum in paraffin embedded tissue sections. $₹$ Histotechnol 1991;14:243-4.

12 Ison CA. Methods of diagnosing gonorrhoea. Genitourin Med 1990;66:453-7.

13 Larsen SA. Syphilis. Clin Lab Med 1989;9:545-57.

14 Hunter EF, Deacon WE, Meyer P. An improved FTA test fo syphilis, the absorption procedure (FTA-ABS). Pub Health Rep 1964;79:410-2.

15 Petersen CS, Rasmussen E, Pedersen NS. Comparison of sorbent preparations used in the fluorescent treponemal antibody absorption (FTA-ABS) test. Dan Med Bull 1990;37:561-2.

16 Petersen CS, Jorgensen BB, Pedersen NS. A sonicate of Reiter treponemes used as sorbing agent in the fluorescent treponemal antibody-absorption (FTA-ABS) test. Dan Med Bul 1991;38:93-6.

17 Hunter EF, Davidson G. The fluorescent treponemal antibody-absorption (FTA-ABS) test for syphilis. Cri Review Clin Lab Sci 1975;1:315-30.

18 Strobel PI Kraus SJ An electron microscopic study of the FTA-ABS "beading" phenomenon with lupus erythematosus sera, using ferritin-conjugated anti-human IgG. $f$ tosus sera, using ferritin-con

19 Scotti TA, Logan L. A specific IgM antibody test in neonatal congenital syphilis. $\mathcal{F}$ Pediatr 1968;73:242-3.

20 Muller F, Lindenschmidt EG. Demonstration of specific $19 S(\operatorname{IgM})$ antibodies in untreated and treated syphilis. $B$ f Venereal Dis 1982;58:12-7.

21 Herbrink $P$, Noorduyn $A$, Dijk WC van. Introduction to enzyme immuno assay In: Bullock $G$, Warhol $M$, Velzen D van, Herbrink P (eds). Techniques in Diagnostic Pathology vol 2: ELISA techniques. Academic Press London 1991:1-21.

22 Veldkamp J, Visser AM. Application of the enzyme-linked immunosorbent assay (ELISA) in the serodiagnosis of syphilis. Br ₹Venereal Dis 1975;51:227-31.

23 Pope V, Hunter EF, Feeley JC. Evaluation of the microenzyme-linked immunosorbent assay with Treponema pallidum antigen. $f$ Clin Microbiol 1982;15:630-4

24 Farshy CE, Hunter EF, Larsen SA, Cerny EH. Double conjugate enzyme-linked immunosorbent assay for conjugate enzyme-linked immunosorbent assay for Clin Microbiol 1984;20:1109-13. 
25 Hunter EF, Farshy CE, Liska SL, Cruce DD, Crawford JA Feeley JC. Sodium desoxycholate-extracted treponema antigen in an enzyme-linked immunosorbent assay for antigen in an enzyme-linked immunoso

26 Farshy CE, Hunter EF, Hensel LO, Larsen SA. Four-step enzyme-linked immunosorbent assay for detection of Treponema pallidum antibody. $\mathcal{F}$ Clin Microbio 1985;21:387-9.

27 Codd AA, Sprott MS, Narang HK, Crone PB, Turner RH. Competitive enzyme-linked immunosorbent assay for Treponema pallidum antibodies. $f$ Med Microbiol 1988;26:153-7.

28 Pedersen NS, Petersen CS, Vejtorp M, Axelsen NH. Serodiagnosis of syphilis by an enzyme-linked immunosorbent assay for IgG antibodies against the Reiter treponeme flagellum. Scand $f$ Immunol 1982;15:341-8.

29 Pedersen NS, Orum O, Mouritsen S. Enzyme-linked immunosorbent assay for detection of antibodies to the venereal disease research laboratory (VDRL) antigen in syphilis. F Clin Microbiol 1987;25:1711-6.

30 Pedersen NS, Pedersen-Sheller J, Ratnam AV, Hira SK Enzyme-linked immunosorbent assay for detection of immunoglobulin $\mathbf{M}$ to nontreponemal and treponema antigens for the diagnosis of congenital syphilis. $\mathcal{f}$ Clin Microbiol 1989;27:1835-40.

31 Harris EN, Gharavi AE, Wasley GD, Hughes GRV. Use of an enzyme-linked immunosorbent assay and the an enzyme-linked iminosorb cardiolipin from patients with syphilis or autoimmune cardiolipin from patients with syphilis
disorders. $\mathcal{F}$ Infect Dis 1988;157:23-31.

32 Costello PB, Green FA. Binding affinity of serum immunoglobulin $G$ to cardiolipin and other phospholipids in patients with systemic lupus erythematosus and syphilis. Infect Immun 1988;56:1738-42.

33 Mouritsen S, Hoier-Madsen M, Wiik A, Orum O, Pederse NS. The specificity of cardiolipin antibodies from syphilis patients and from patients with systemic lupus erythematosus. Clin Exp Immunol 1989;76:178-83.

34 Loizou S, Mackworth-Young G, Cofiner C, Walport MJ. Heterogeneity of binding reactivity of different phospholipids of antibodies from patients with systemic lupus erythematosus (SLE) and with syphilis. Clin Exp Immuno 1990;80:171-6.

35 Stevens RW, Schmitt ME. Evaluation of an enzyme-linked immunosorbent assay for treponemal antibody. $₹ \mathrm{Clin}$ Microbiol 1985;21:399-402.

36 Moyer NP, Hudson JD, Hausler WJ Jr. Evaluation of the Bio-EnzaBead test for syphilis. $f$ Clin Microbio 1987;25:619-23.

37 Burdash NM, Hinds KK, Finnerty JA, Manos JP. Evaluation of the syphilis Bio-EnzaBead assay for the detection of treponemal antibody. $\mathcal{f}$ Clin Microbio 1987;25:808-11.

38 Larsen SA, Hambie EA, Cruce DD. Review of the standard tests for syphilis and evaluation of a new commercial ELISA, the syphilis Bio-EnzaBead test. $f$ Clin Lab Anal 1987;1:300-7.

39 Young H, Moyes A, McMillan A, Robertson DHH. Screening for treponemal infection by a new enzyme immunoassay. Genitourin Med 1989;65:72-8.

40 Levefre J-C, Bertrand M-A, Bauriaud R. Evaluation of the Captia immunoassays for the detection of immunoglobulins $G$ and $M$ to Treponem
Microbiol 1990;28:1704-7.

41 Ross J, Moyes A, Young H, McMillan A. An analysis of false positive reactions with the Captia Syph G EIA. Genitourin Med 1991;67:408-10.

42 Young H, Moyes A, McMillan A, Patterson J. Enzyme immunoassay for anti-treponemal IgG: Screening or confirmatory test? $\mathcal{F}$ Clin Pathol 1992;45:37-41.

43 Muller F, Moskophidis M, Borkhardt HL. Detection of immunoglobulin $M$ antibodies to Treponema pallidum in a modified enzyme-linked immunosorbent assay. Eur $\mathcal{F}$ Clin Microbiol 1987;6:35-9.

44 Cerny EH, Farshy CE, Hunter EF, Larsen SA. Rheumatoid factor in syphilis. $\mathcal{f}$ Clin Microbiol 1985;22:89-94.
45 IJsselmuiden OE, Sluis J van der, Mulder A, Bolton KP, Eijk RVW van. An IgM capture enzyme linked immunoEijk RVW van. An IgM capture enzyme linked immunosorbent assay to detect IgM antibodies to treponemes in

46 Radolf JD, Lernhardt EB, Fehniger TE, Lovett MA Radolf JD, Lernhardt EB, Fehniger TE, Lovett MA.
Serodiagnosis of syphilis by enzyme-linked immunosorbent assay with purified recombinant Treponema pallidum antigen 4D. F Infect Dis 1986;153:1023-7.

47 Rodgers GC, Laird WJ, Coates SR, Mack DH, Huston M Sninsky JJ. Serological characterization and gene localization of an Escherichia coli-expressed 37 kilodalton Treponema pallidum antigen. Infect Immun 1986; 53:16-25.

48 Schouls LM, IJsselmuiden OE, Weel J, Embden JDA van. Overproduction and purification of Treponema pallidum Overproduction and purification of Treponema palidum
recombinant-DNA-derived proteins TmpA and TmpB and their potential use in serodiagnosis of syphilis. Infect and their potential use in

49 IJsselmuiden OE, Schouls LM, Stolz E, et al. Sensitivity and specificity of an enzyme-linked immunosorbent assay using the recombinant DNA-derived Treponema pallidum protein TmpA for serodiagnosis of syphilis and the potential use of TmpA for assessing the effect of antibiotic therapy. ₹ Clin Microbiol 1989;7:152-7.

50 Hay PE, Clarke JR, Strugnell RA, Taylor-Robinson D, Goldmeier D. Use of the polymerase chain reaction to detect DNA sequences specific to pathogenic treponemes in cerebrospinal fluid. FEM Microbiol Lett 1990 68:233-8.

51 Hay PE, Clarke JR, Taylor-Robinson D, Goldmeier D. Detection of treponemal DNA in the CSF of patients Detection of treponemal DNA in the CSF of patients
with syphilis and HIV infection using the polymerase with syphilis and Hitu infection using the polym

52 Noordhoek GT, Wolters ECh, Jonge MEJ de, Embden JDA van. Detection by polymerase chain reaction of Treponema pallidum DNA in cerebrospinal fluid from neurosyphilis patients before and after antibiotic treatment. $\mathcal{f}$ Clin Microbiol 1991;29:1976-84

53 Burstain JM, Grimprel E, Lukehart SA, Norgard MV Radolf JD. Sensitive detection of Treponema pallidum by using the polymerase chain reaction. I Clin Microbio 1991;29:62-9.

54 Grimprel E, Sanchez J, Wendel GD, et al. Use of polymerase chain reaction and rabbit infectivity testing to detect Treponema pallidum in amniotic fluid, fetal and neonatal sera, and cerebrospinal fluid. $\mathcal{f}$ Clin Microbiol neonatal sera, and

55 Noordhoek GT, Hermans PWM, Paul AN, Schouls LM, Slứs JJ van der, Embden JDA van. Treponema pallidum subspecies pallidum (Nichols) and Treponema pallidum subspecies pertenue (CDC 2575) differ in at least one nucleotide: comparison of two homologous antigens. Microbial Pathogen 1989;6:29-42.

56 Noordhoek GT, Wieles B, Sluis JJ van der, Embden JDA van. Polymerase chain reaction and synthetic DNA probes: a means of distinguishing the causative agents of syphilis and yaws. Infect Immun 1990;58:2011-3.

57 Noordhoek GT, Cockayne A, Schouls LM, Meloen RH, Stolz E, Embden JDA van. A new attempt to distinguish serologically the subspecies of $T$ pallidum causing syphilis serologically the subspecies of $T$ pallidum causin
and yaws. $\mathcal{F}$ Clin. Microbiol 1990;28:1600-7.

58 Lukehart SA, Hook III EW, Baker-Zander SA, Collier AC Critchlow CW, Handsfield $\mathrm{HH}$. Invasion of the central nervous system by Treponema pallidum: implications for diagnosis and treatment. Ann Intern Med 1988;109:855-62.

59 Tramont EC. Syphilis in the AIDS era. $N$ Engl $f$ Med 1987;316:1600-1.

60 Hicks CB, Benson PM, Lupton GP, Tramont EC Seronegative secondary syphilis in a patient with the human immunodeficiency virus (HIV) with Kaposi sarcoma. Ann Intern Med 1987;107:492-5.

61 Haas JS, Bolan G, Larsen SA, Clement MJ, Bacchetti P, Moss AR. Sensitivity of treponemal tests for detecting prior treated syphilis during human immunodeficiency prior treated syphilis during human immuno
virus infection. $¥$ Infect Dis 1990;162:862-6. 